\title{
Awareness of Women Regarding Vaginal Discharge
}

\author{
Ebtisam Hashem Zaher ${ }^{1}$, Nahed Fikry Hassan $\operatorname{Khedr}^{2} \&$ Hanan Awad M \\ Elmashad ${ }^{3}$ \\ Researcher B.Sc. Nursing ${ }^{1}$, Assistant Professor of woman health \&Midwifery nursing department, Faculty of \\ Nursing, Mansoura University ${ }^{2}$, Lecturer of Woman Health \& Midwifery nursing, Faculty of Nursing - \\ Mansoura University.
}

\begin{abstract}
:
The present study aimed to assess women awareness regarding vaginal discharge.

Study design: Cross sectional design was utilized.

Study sitting: The study was conducted at 17 faculties at Mansoura University.

Study sample: A total of 500 employees selected by systematic random sample.

Tool of data collection: A structured interviewing questionnaire was used. It included five parts to assess general characteristics, obstetrical history, knowledge and health seeking behavior regarding vaginal discharge and the incidence of abnormal vaginal discharge among the studied sample.

Results: The finding of this study revealed that less than quarter of the employees complained of abnormal vaginal discharge. More than half of studied women had bad knowledge score. More than half of them did not consider vaginal discharge as a serious problem that need medical examination. There was a highly statistical significant relation between total knowledge score level and using reusable sanitary pad and abnormal vaginal discharge.

Conclusion: The abnormal vaginal discharge was common among women at Mansoura University. In addition, the women had poor awareness regarding vaginal discharge.

Recommendations: This study recommended that the health care provider should prepare and implement health programs for raising the community awareness about vaginal discharge characteristics and early medical checkup that will improve hygienic practices and therefore decrease abnormal vaginal discharge.
\end{abstract}

Keywords: Vaginal discharge, Awareness, Knowledge, Practices.

\section{Introduction}

The complaint of abnormal vaginal discharge is common among women in the reproductive age. The vaginal discharge may be due to physiological or pathological condition. The physiological discharge is healthy and normal for the women of the reproductive age. During the menstrual cycle, the type and the quantity of the cervical mucus changes(Sobel, 2011). Vaginal discharge that differs in odor, color, consistency or significantly decreases or increases in amount, may be due to an underlying problem like an infection (Hirsch, 2013).

Abnormal vaginal discharge (AVD) is not a disease for itself but it is a symptom of other diseases as reproductive tract infections and sexual transmitted diseases, and if it isn't treated well it may lead to severe complications as pelvic inflammatory disease, ectopic pregnancy, congenital anomalies, prognosis of genital tract malignancy, so early detection and treatment of abnormal vaginal discharge decreases the maternal morbidity and mortality (Maria et al., 2013).

The causes of abnormal vaginal discharge may be infective or non-infective. The infective causes may be (non-sexually transmitted) as bacterial vaginosis and candida or (sexual transmitted) like neisseria gonorrhea, trichomonas vaginalis. On the other hand, the non-infective causes of abnormal vaginal discharge are foreign bodies (e.g. condoms, retained tampons), genital tract malignancy, fistulae, cervical polyps, allergic reaction and douching. Others causes like the use of antibiotic, steroid or birth control pills, diabetes, douches, scented soaps or lotions, bubble bath, pelvic inflammatory disease (PID), pelvic infection after surgery, vaginal atrophy (Web med ., 2015).

The prevalence of abnormal vaginal discharge was $26.3 \%$ in the rural area of India (Komal et al., 2014). Abnormal vaginal discharge (AVD) is symptom of reproductive tract infections (RTIs) and sexual transmitted diseases (STDs).WHO estimates that there are more than 340 million new patients of sexually transmitted infections every year and $75-85 \%$ of them from the developing countries and lead to sever complication on the women health (Kumar\& Padmaja 2016). The women who complain of abnormal vaginal discharge don't seek medical examination except the complaint become intolerable and hinder the daily work, this may be due to modesty from reveal the genital area or felling shame to be examined by male doctor (Li et al., 2010). 
The nurse has important role in increasing the awareness of women regarding the reproductive tract infection; causes, prophylactic measures, complications and signs of infection. Also nurse should instruct the woman how to differentiate between the normal and abnormal vaginal discharge and healthy behaviors and ask the woman to avoid the unhealthy behavior as using vaginal douch, using perfumes or any unhealthy herbal treatment (British Medical Journal, 2013).

\section{Significance of the study}

The incidence of abnormal vaginal discharge is high particularly in developing countries with low socioeconomic level as in Egypt (Abbas et al., 2016). Abnormal vaginal discharge (AVD) is the most common symptom of reproductive tract infections (RTIs) and sexual transmitted diseases (STDs). The women's awareness about abnormal vaginal discharge has a direct effect on their attitudes and practices. Health practices are important for health and wellbeing of women. Abnormal vaginal discharge may be more likely to develop in women who do unhealthy practices which affect their reproductive health negatively as using vaginal douche and sprays (Sobel, 2015) \& (Shaaban et al., 2013). The misconception of the woman about the causes, correct health behavior, self-prevention and culture of silence regarding abnormal vaginal discharge، all of these lead to increase the incidence of abnormal vaginal discharge and its complications (Li et al., 2010). So this study was conducted to assess the awareness of women regarding vaginal discharge.

\section{Aim of the study}

This study aimed to assess women awareness regarding vaginal discharge.

\section{Research questions}

1. What's the women's awareness regarding vaginal discharge?

2. What are the health seeking behavior which taken by the women when complaining of abnormal vaginal discharge?

3. Dose there are relations between women's hygienic practices and complaining of abnormal vaginal discharge?

\section{Subjects and Methods}

1. Study design: Across sectional study was conducted.

2. Study Setting: The study was carried out in 17 faculties at Mansoura University.

3. Study Subjects: The study was conducted on 500 employees selected by systematic random sample. All married, virgin, widows and divorced women at Mansoura University. The women who were in vacations and who refused to participate in the study were replaced by other

Sample size: The calculated sample size of the study is 384, using the following formula (Daniel, 1999).

$$
\mathbf{Z}^{2} * \mathbf{P} *(1-\mathbf{P})
$$

$\mathbf{n}=\frac{\mathbf{d}^{2}}{\mathrm{~W}}$

Where $\mathrm{Z}=1.96$ for $95 \%$ confidence level. $\mathrm{p}=$ expected prevalence $(50 \%)$.

$$
\mathrm{d}=\text { precision }(\text { Margin of error })=0.05
$$

The researcher increased the sample size to 500 women to increase the accuracy of the study.

Total number of women at Mansoura University is $\mathbf{2 7 6 3}$ women and the total number of faculties at Mansoura University is 17 faculties, (Statistical Map of Mansoura University 2012-2013).

The number of women from each faculty was calculated according to their percentage to the total number of all women at Mansoura University:

\section{Number of women at the faculty}

$\mathbf{n}=$

Total number of all women at Mansoura University (2763)

Sampling type: systematic random sample.

\section{Tool of data collection}

Structured interviewing questionnaire was designed by the researcher to collect data. It consisted of 5 parts:

Part 1: was designed to assess the general characteristics of the women such as (age, marital status...etc.).

Part 2: was designed to assess the obstetric history of the women as (number of pregnancy, number of children and mode of delivery....etc.).

Part 3: was designed to assess the knowledge regarding vaginal discharge. Scoring system for employee's knowledge: 
Each correct answer was scored $=1$ and incorrect answer was scored=0. The total score of knowledge was 19 points, which represents $100 \%$. Final knowledge assessment score was as good knowledge $>75 \%$, fair knowledge from $50 \%$ to $75 \%$, and poor knowledge less than $50 \%$.

Part 4: was designed to assess the complaining of abnormal vaginal discharge and its characteristics among the studied women.

Part 5: was designed to assess women's hygienic practices.

\section{Pilot study}

A pilot study was carried out on $10 \%$ of the sample to test applicability and clarity of the tool, the tool were tested to confirm that the questions were suitable, easy to understand, cover the aim of the study and carry the same meaning which designed for it.

Validity: The internal validity of the tool was evaluated by five experts in the field and the notices were considered.

Reliability: Cronbach's alpha was calculated for knowledge tool equal 0.716 and calculated for practices equal 0.731

\section{Field work}

- The researcher attended at each faculty at Mansoura University from 9:30 am to 1:30 pm for three days per week, till complete the predetermined sample size.

- Data collection extended from March 2015 to October 2015.

- The researcher went to all faculties and explained the aim of the study to the administration and took permission to conduct the study and took menu of the employee's names and took the sample from it by systematic random sample.

- The researcher met every employee and introduced herself to each one.

- The researcher explained the aim of the study to the employees to obtain the informed written consent to be involved in the study.

- Complete instructions regarding answering the questionnaire sheet were given.

- The sheet took 25 to 35 minutes to be completed.

\section{Ethical consideration}

Ethical approval was obtained from the research ethics committee of the faculty of Nursing - Mansoura University. An official permission to conduct the study was obtained from the responsible administration at Mansoura University. All relevant ethical aspects were considered for ensuring employee's privacy and confidentiality of the collected data through; gaining written consent for participation in the study, explaining the purpose of the study and right to refuse to continue participation.

\section{Statistical analysis}

The data were collected, coded, computed, and statistically analyzed by using SPSS software program (version 16.) the data were presented in tables and graphs as frequency and percentage. The comparison between groups was done using chi square test (x2) and the difference is considered significant at $\mathrm{P} \leq 0.05$.

\section{Results}

Table (1): Frequency Distribution of General Characteristics among Women

\begin{tabular}{|lll|}
\hline Items & No. $(\mathbf{n}=\mathbf{5 0 0})$ & $\%$ \\
\hline Age groups(in years): & & \\
Less than 25 & 65 & 13.0 \\
$25-30$ & 131 & 26.2 \\
$31-36$ & 138 & 27.6 \\
$37-42$ & 79 & 15.8 \\
More than 42 & 87 & 17.4 \\
Marital status: & & \\
Single & 48 & 9.6 \\
Married & 415 & 83.0 \\
Divorced & 22 & 4.4 \\
Widow & 15 & 3.0 \\
Educational level: & & \\
Cannot read and write & 9 & 1.8 \\
Basic & 15 & 3.0 \\
Secondary & 12 & 2.4 \\
Technical & 236 & 47.2 \\
University & 218 & 43.6 \\
Others & 10 & 2.0 \\
& &
\end{tabular}




$\begin{array}{lll}\text { Religion: } & & \\ \text { Muslim } & 488 & 97.6 \\ \text { Christian } & 12 & 2.4 \\ & & \\ \text { Occupations: } & & 85.0 \\ \text { Officers } & 425 & 15.0 \\ \text { Cleaner } & 75 & 55.0 \\ \text { Residence: } & & 45.0 \\ \text { Rural } & 275 & \end{array}$

Table (1): Shows that $27.6 \%$ of the women's age ranged from $31-36$ years old, and $83 \%$ of them were married. Concerning the level of education, it was found that $47.2 \%$ of them had technical education and $1.8 \%$ of them couldn't read and write. The majority of women were Muslim and officers $(97.6 \%, 85 \%$ respectively). Regarding the residence, it was found that $55 \%$ of the women from rural areas.

Table (2): Frequency Distribution of the Incidence and Characteristics of Abnormal Vaginal Discharge among the Women

\begin{tabular}{|c|c|c|}
\hline Items & No. $(n=500)$ & $\%$ \\
\hline In the past years & Complain of abnormal vaginal discharge & \\
\hline Yes & 349 & 69.8 \\
\hline No & 151 & 30.2 \\
\hline \multicolumn{3}{|l|}{ At the time of the study } \\
\hline Yes & 117 & 23.4 \\
\hline No & 383 & 76.6 \\
\hline \multicolumn{3}{|c|}{ Characteristics of abnormal vaginal discharge $(n=117)$} \\
\hline \multicolumn{3}{|c|}{ The color of vaginal discharge } \\
\hline white & 60 & 51.3 \\
\hline yellow & 46 & 39.3 \\
\hline brown & 5 & 4.3 \\
\hline red & 4 & 3.4 \\
\hline black & 2 & 1.7 \\
\hline \multicolumn{3}{|c|}{ The beginning of the discharge } \\
\hline one week & 22 & 18.8 \\
\hline 2weeks & 7 & 6.0 \\
\hline one month & 26 & 22.2 \\
\hline more than 2 month & 62 & 53.0 \\
\hline \multicolumn{3}{|l|}{ The consistency } \\
\hline Thick & 63 & 53.8 \\
\hline Creamy & 41 & 35.1 \\
\hline Thin & 13 & 11.1 \\
\hline \multicolumn{3}{|l|}{ The odor } \\
\hline cruddy & 37 & 31.6 \\
\hline moderate & 43 & 36.8 \\
\hline odorless & 37 & 31.6 \\
\hline \multicolumn{3}{|l|}{ Associated symptoms } \\
\hline Itching: & 82 & 70.1 \\
\hline Lower abdominal pain & 86 & 73.5 \\
\hline
\end{tabular}

Table (2) Presents that more than two third of the women complained of abnormal vaginal discharge in their last years $(69.8 \%)$. The incidence of abnormal vaginal discharge at the time of the study was $(23.4 \%)$. The color of vaginal discharge was white among $51.3 \%$ of them. Also, more than half of the women complained of abnormal vaginal discharge for two months, and had thick discharge (53\%, 53.8\% respectively) and $11.1 \%$ of them reported that it was thin. More than one third of them reported that the discharge had a moderate odor $(36.8 \%)$. More than two third of women complained from itching and lower abdominal pain $(70.1 \%, 73.5 \%$ respectively). 
Table (3): Frequency Distribution of Knowledge regarding Vaginal Discharge among the Women

\begin{tabular}{|c|c|c|c|c|}
\hline \multirow{3}{*}{ Items } & \multirow{2}{*}{\multicolumn{2}{|c|}{ Correct answer }} & \multicolumn{2}{|c|}{ In Correct answer } \\
\hline & & & & \\
\hline & NO. & $\%$ & No. & $\%$ \\
\hline \multicolumn{5}{|l|}{ Characteristics of normal vaginal discharge: } \\
\hline Color & 272 & 54.4 & 228 & 45.6 \\
\hline Consistency & 310 & 62.0 & 190 & 38.0 \\
\hline Odor & 337 & 67.4 & 163 & 32.6 \\
\hline \multicolumn{5}{|l|}{ Abnormal vaginal discharge: } \\
\hline Color & 235 & 47.0 & 265 & 53.0 \\
\hline Causes & 236 & 47.2 & 264 & 52.8 \\
\hline Differentiation of vaginal discharge during month & 182 & 36.4 & 318 & 63.6 \\
\hline Periods of increased abnormal vaginal discharge & 253 & 70.6 & 147 & 29.4 \\
\hline Causes of increased abnormal vaginal discharge in pregnancy & 224 & 44.8 & 276 & 55.2 \\
\hline Changes in vaginal discharge which indicate diseases & 313 & 62.6 & 187 & 37.4 \\
\hline $\begin{array}{l}\text { The cause of cheesy white vaginal discharge accompanied } \\
\text { with burning sensation and edematous vulva and vagina }\end{array}$ & 121 & 24.2 & 379 & 75.8 \\
\hline Risk factors for increasing vulnerability to fungal infection & 171 & 34.2 & 329 & 65.8 \\
\hline Signs and symptoms of fungal infection & 278 & 55.6 & 222 & 44.4 \\
\hline Prophylactic measures from vaginal infection & 429 & 85.8 & 71 & 14.2 \\
\hline Condom decrease spread of infection & 299 & 59.8 & 201 & 40.2 \\
\hline Vaginal infection may lead to preterm labor & 200 & 40 & 300 & 60 \\
\hline $\begin{array}{l}\text { The bloody vaginal discharge at the end of pregnancy may be } \\
\text { a labor show }\end{array}$ & 369 & 73.8 & 131 & 26.2 \\
\hline $\begin{array}{l}\text { The yellow and green color of vaginal discharge indicate } \\
\text { chronic vaginal infection }\end{array}$ & 266 & 53.2 & 234 & 46.8 \\
\hline \multicolumn{5}{|l|}{ Trichomonas } \\
\hline Signs & 81 & 16.2 & 419 & 83.8 \\
\hline Transmitted through sexual intercourse & 67 & 13.4 & 433 & 86.6 \\
\hline
\end{tabular}

Table (3) Illustrates that more than half of women had correct answer regarding the color of normal vaginal discharge, the consistency of normal vaginal discharge and odor of normal vaginal discharge $(54.4 \%, 62 \%$ $\& 67.4 \%$ respectively). More than half of women had incorrect answer regarding vaginal discharge changes during month, the colors of abnormal vaginal discharge, the causes of abnormal vaginal discharge and the causes of increased vaginal discharge in pregnancy $(63.6 \%, 53 \%, 52.8 \% \& 55.2 \%$ respectively). More than half of women had correct answer regarding the changes in vaginal discharge which indicate diseases, signs and symptoms of fungal infection, condom decrease spread of infection, the yellow and green color of vaginal discharge indicate chronic vaginal infection $(62.6 \%, 55.6 \%, 59.8 \% \& 53.2 \%$ respectively). The majority of the studied group had correct answer regarding the prophylactic measures from vaginal infection and the bloody vaginal discharge at the end of pregnancy may be a labor show $(85.8 \% \& 73.8 \%)$. The majority of the studied group had incorrect answer regarding the cause of cheesy white vaginal discharge accompanied with burning sensation and edematous vulva and vagina, risk factors for increasing vulnerability to fungal infection, vaginal infection may lead to preterm labor, signs of trichomonas and trichomonas transmitted through sexual intercourse $(75.8 \%, 65.8 \%, 60 \%$, $83.8 \%$ \&86.6\% respectivly).

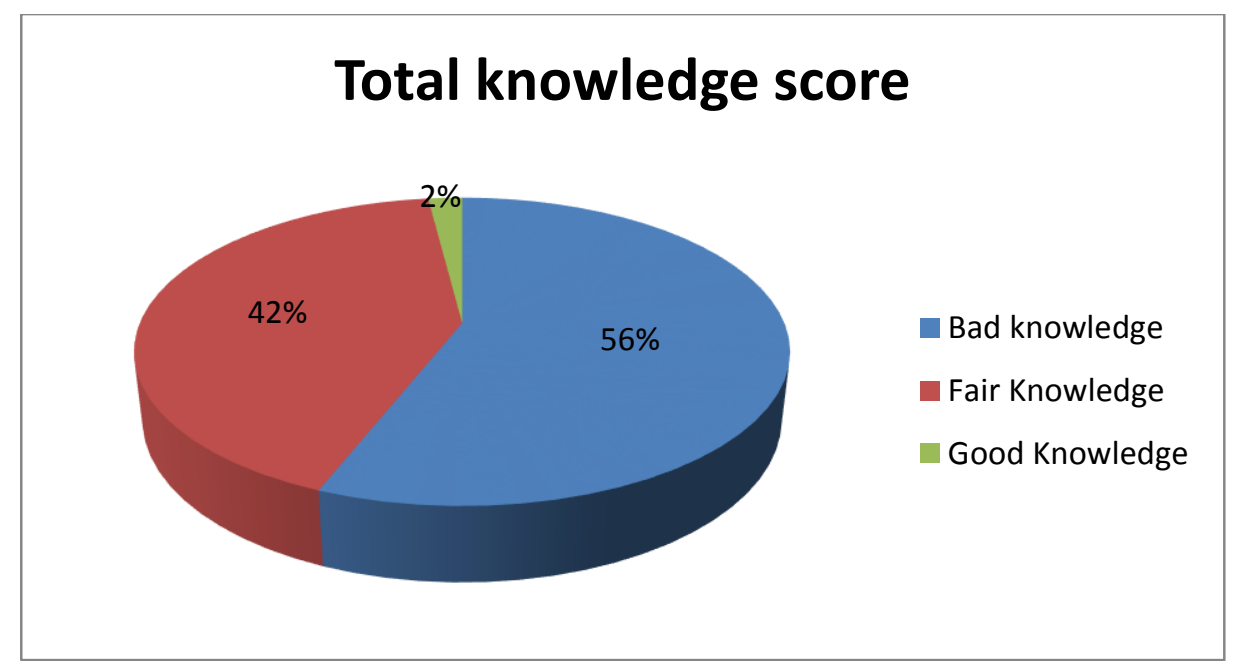

Figure (1) Frequency Distribution of Women according to Level of Knowledge about Vaginal Discharge. 
Table (4): Personal Hygienic Practices among Women

\begin{tabular}{|c|c|c|}
\hline Items & $\begin{array}{c}\text { No. } \\
(\mathrm{n}=500)\end{array}$ & $\%$ \\
\hline \multicolumn{3}{|l|}{ Daily hygienic practices of genitalia } \\
\hline External washing. & 171 & 34.2 \\
\hline Internal washing with finger. & 179 & 35.8 \\
\hline Douching. & 47 & 9.4 \\
\hline Sitz bath & 72 & 14.4 \\
\hline Wash genital area and sprinkle perfumes. & 31 & 6.2 \\
\hline \multicolumn{3}{|l|}{ Bathing: } \\
\hline Every day & 389 & 77.8 \\
\hline Every 2 days & 79 & 15.8 \\
\hline Every 3 days & 20 & 4.0 \\
\hline Every week & 12 & 2.4 \\
\hline \multicolumn{3}{|c|}{ Hand washing before and after cleaning genital area } \\
\hline Yes & 71 & 14.2 \\
\hline No & 429 & 85.8 \\
\hline \multicolumn{3}{|l|}{ Use cotton underwear } \\
\hline Yes & 348 & 69.6 \\
\hline No & 152 & 30.4 \\
\hline \multicolumn{3}{|l|}{ The preferred underwear } \\
\hline Tight & 31 & 6.2 \\
\hline Wide & 70 & 14.0 \\
\hline Comfortable & 399 & 79.8 \\
\hline \multicolumn{3}{|l|}{ Changing under wear: } \\
\hline Every day & 268 & 53.6 \\
\hline Every two days & 39 & 7.8 \\
\hline Every week & 4 & 0.8 \\
\hline More than one per day as needed & 189 & 37.8 \\
\hline \multicolumn{3}{|l|}{ Remove the genital hair } \\
\hline Yes & 481 & 96.2 \\
\hline No & 19 & 3.8 \\
\hline \multicolumn{3}{|l|}{ The way of removal } \\
\hline Sweat & 349 & 72.6 \\
\hline Hair removal cream & 76 & 15.8 \\
\hline Hair removal machine & 56 & 11.6 \\
\hline \multicolumn{3}{|l|}{ The time interval of hair removal } \\
\hline Every 20 days & 146 & 30.4 \\
\hline Every month & 283 & 58.8 \\
\hline Every 2 month & 34 & 7.1 \\
\hline More 2 month & 18 & 3.7 \\
\hline
\end{tabular}

Table (4) Shows that $35.8 \%$ of the women used internal washing with finger when they cleaned the genitalia and $34.2 \%$ were washing the genitalia externally. Regarding to the utilized underwear, $69.6 \%$ of them used cotton underwear and $(53.6 \%)$ changed it daily. Regarding to hair removal, the majority of them removed genital hair (96.2\%) through utilized sweat (72.6\%).

Table (5): Women's Hygienic Practices during Menstruation

\begin{tabular}{|lc|}
\hline Items & No.(n=500) \\
\hline Bathing during menses: & $\%$ \\
Taking shower every day during menses & 333 \\
Every 2 days & 96.6 \\
Every 3 days & 18.4 \\
never take a bath during menses & 4.0 \\
Sanitary pads: & 55 \\
Disposable sanitary pad & 11.0 \\
Reused homemade pad or old cloth pad & 331 \\
Both & 86 \\
Change sanitary pad per day & 86.2 \\
One & 17.6 \\
Two & 16.2 \\
Three & 51 \\
As needed & 28 \\
Washing of reused homemade pad before reused & 137 \\
Water and soap & 27.4 \\
Water and soap and boiling & 19.8 \\
\hline
\end{tabular}

Table (5) Shows that more than two third of the women practiced daily shower during menstruation and used disposable sanitary pad during menses (66.6\% and $66.2 \%$ respectively), versus $17.6 \%$ of them used reusable homemade pad or old cloth pads. More than half of those who were using reusable homemade pads washed them with soap and water and boiled them. 
Table (6): Women's Behavior Regarding Early Seeking Medical Examination when Complaining of Abnormal Vaginal Discharge

\begin{tabular}{|c|c|c|}
\hline Items & No. $(n=500)$ & $\%$ \\
\hline \multicolumn{3}{|c|}{ Seeking medical examination when complain of abnormal vaginal discharge } \\
\hline Yes & 324 & 64.8 \\
\hline No & 176 & 35.2 \\
\hline \multicolumn{3}{|l|}{ Causes of seeking medical examination } \\
\hline Fear of serious disease & 104 & 32.09 \\
\hline In ability to tolerate abnormal symptoms & 93 & 28.7 \\
\hline The case become worse with time. & 70 & 21.6 \\
\hline Self-Administered drugs without benefit & 27 & 8.4 \\
\hline Improved after had administered medication & 20 & 6.17 \\
\hline Fear of affected with sexually transmitted diseases & 10 & 3.08 \\
\hline \multicolumn{3}{|l|}{ Causes of not seeking medical examination } \\
\hline Abnormal vaginal discharge is social stigma & 4 & 2.27 \\
\hline It is simple and there is no need for examination & 67 & 39.2 \\
\hline Lack of awareness & 30 & 17.6 \\
\hline Shyness from reveal the genitalia & 75 & 42.6 \\
\hline
\end{tabular}

Table (6): Illustrates that $64.8 \%$ of the women were sought medical advice when they complained of abnormal vaginal discharge, the most common cause for seeking examination was fear from serious diseases followed by in ability to tolerate the abnormal symptoms ( $32 \% \& 28.7 \%$ respectively). More than one third of the women didn't seek medical examination(35.2\%), and the causes were the abnormal vaginal discharge was simple and no need for examination, feel shyness from reveal the genitalia, lack of awareness and considered abnormal vaginal discharge as social stigma among $(39.2 \%, 42.6 \%, 17.6 \% \& 2.2 \%$ respectively).

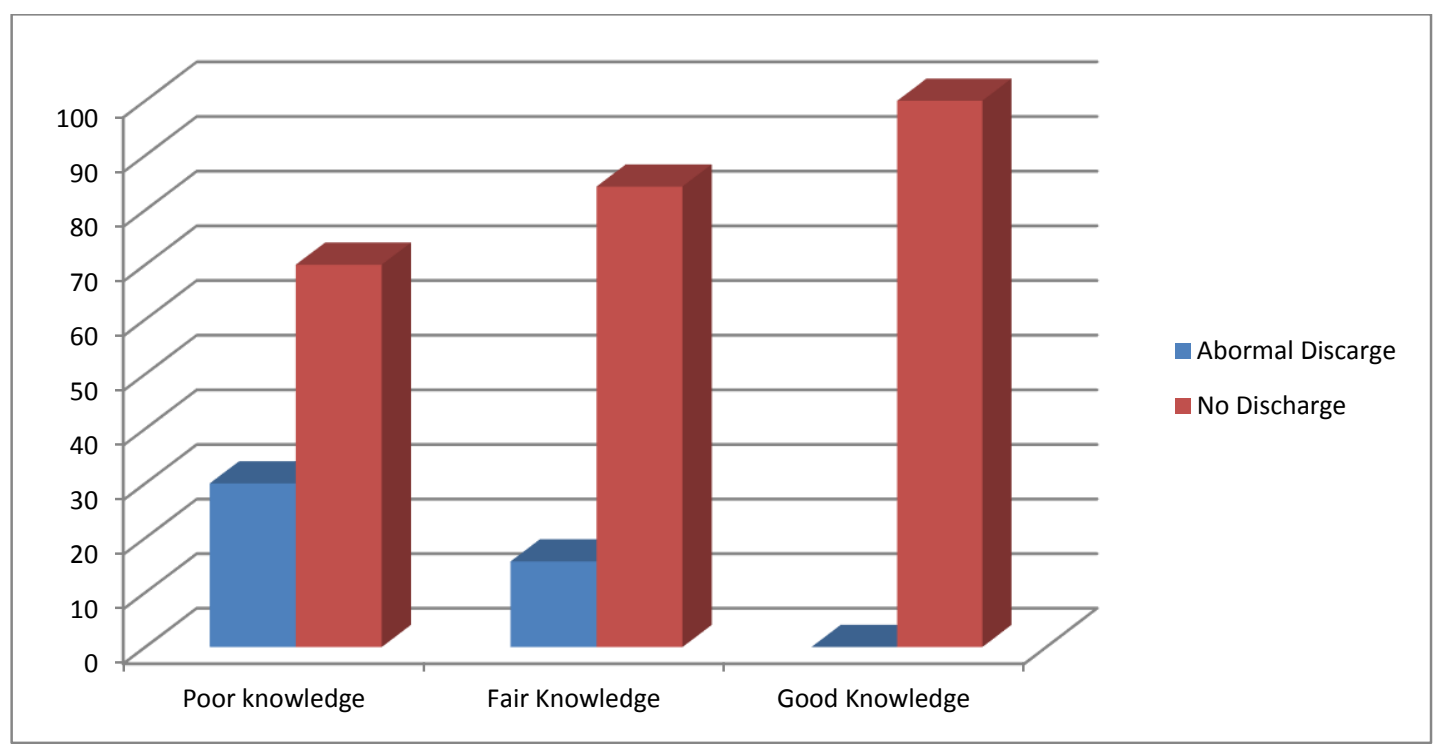

Figure (2): Correlation between the Level of Knowledge and Complaining of Abnormal Vaginal Discharge.

Table (7): Correlation between Causes of Seeking Medical Examination and Complaining of Abnormal Vaginal Discharge.

\begin{tabular}{|c|c|c|c|c|c|}
\hline \multirow[t]{2}{*}{ Causes of Seeking Medical Examination } & \multicolumn{2}{|c|}{$\begin{array}{c}\text { normal vaginal } \\
\text { discharge }\end{array}$} & \multicolumn{2}{|c|}{$\begin{array}{c}\text { Abnormal vaginal } \\
\text { discharge }\end{array}$} & \multirow[t]{2}{*}{ Significance test } \\
\hline & No. $(n=254)$ & $\%(100)$ & No. $(n=70)$ & $\%(100)$ & \\
\hline Fear of serious disease & 93 & 89.4 & 11 & 10.6 & $\mathbf{X} 2=21.96$ \\
\hline Cannot bear symptoms & 60 & 64.5 & 33 & 35.5 & $\mathbf{P}=0.000^{*}$ \\
\hline Fear of sexual transmitted diseases & 10 & 100 & 0 & 0.00 & \\
\hline No improvement after self-treatment & 19 & 70.4 & 8 & 29.6 & \\
\hline Improved before, after taking medical treatment & 16 & 80.0 & 4 & 20.0 & \\
\hline Case become worse with the time & 56 & 80.0 & 14 & 20.0 & \\
\hline Total $\quad 324$ & & & & & \\
\hline
\end{tabular}

Table (7) Shows that, there was a statistical significant relation between complaining of vaginal discharge and causes of seeking medical examination. The majority of women who sought examination because they fear from serious diseases had no abnormal vaginal discharge (89.4\%). All the women who fear from sexual transmitted diseases hadn't abnormal vaginal discharge, more than one third $(35.5 \%)$ of women who didn't seek 
examination till they cannot tolerate the abnormal symptoms were the most women who had abnormal vaginal discharge.

Table (8): Correlation between Complaining of Abnormal Vaginal Discharge and Menstrual Hygienic Practices.

\begin{tabular}{|c|c|c|c|c|}
\hline \multirow[t]{2}{*}{ Items } & \multicolumn{2}{|c|}{ Normal vaginal discharge } & \multicolumn{2}{|c|}{ Abnormal vaginal discharge } \\
\hline & No. $(n=383)$ & $\%$ & No. $(n=117)$ & $\%$ \\
\hline \multicolumn{5}{|l|}{ Times of change sanitary pad in the day } \\
\hline One & 18 & 64.3 & 10 & 35.7 \\
\hline Two, Three and as needed & 365 & 77.4 & 107 & 22.6 \\
\hline \multicolumn{5}{|l|}{$\mathrm{X} 2=2.51$} \\
\hline \multicolumn{5}{|l|}{$P=0.113 *$} \\
\hline \multicolumn{5}{|l|}{ Bathing during menses } \\
\hline every day during menses & 254 & 76.3 & 79 & 23.7 \\
\hline After 2 days from the beginning of menses & 81 & 88.8 & 11 & 12 \\
\hline After 3 days from the beginning of menses & 15 & 75 & 5 & 25 \\
\hline Never take a bath during menses & 33 & 60 & 22 & 40 \\
\hline Total 500 & 383 & $100 \%$ & 117 & 23.4 \\
\hline \multicolumn{5}{|l|}{ Sanitary pads } \\
\hline Disposable sanitary pad & 264 & 79.8 & 67 & 20.2 \\
\hline Reused homemade pad or old cloth pad & 56 & 71.8 & 22 & 28.2 \\
\hline Both & 63 & 69.2 & 28 & 30.8 \\
\hline Total & 383 & 100 & 117 & 100 \\
\hline$X 2=5.678 \quad P=0.05$ & & & & \\
\hline
\end{tabular}

Table (8) Shows that there was statistical significant difference between types of sanitary pad utilized and the presence of abnormal vaginal discharge $(x 2=5.6, \mathrm{p}=0.05)$. There was increase in the abnormal vaginal discharge in those women who used reusable sanitary pads than those who used disposable sanitary pads. There was no statistically difference between abnormal vaginal discharge and changing sanitary pads per day $(\mathrm{x} 2=2.51$, $\mathrm{p}=0.113$ ).

Table (9): Correlation between Complaining of Abnormal Vaginal Discharge and Hygienic Practices followed by the Women

\begin{tabular}{|c|c|c|c|c|c|}
\hline \multirow{2}{*}{ Hygienic Practices } & \multicolumn{2}{|c|}{ Normal vaginal discharge } & \multicolumn{2}{|c|}{ Abnormal vaginal discharge } & \multirow{2}{*}{ Significance test } \\
\hline & No. $(n=383)$ & $\%$ & No. $(n=117)$ & $\%$ & \\
\hline \multicolumn{6}{|l|}{ Daily hygienic practice of genitalia } \\
\hline External washing & 141 & 36.8 & 30 & 25.6 & $\chi 2=9.817$ \\
\hline Douching & 40 & 10.4 & 7 & 6.0 & \\
\hline Sit in bath & 54 & 14.1 & 18 & 15.4 & \\
\hline Wash genital area and sprinkle perfume & 21 & 5.5 & 10 & 8.5 & \\
\hline No & 109 & 71.7 & 43 & 28.2 & \\
\hline Yes & 274 & 78.7 & 74 & 21.3 & \\
\hline
\end{tabular}

Table (9) shows that, there was statistical significant relation between complaining of abnormal vaginal discharge and genital hygienic practice of women $(\chi 2=9.817$, P 0.044). Abnormal vaginal discharge was decreased in the women who used external washing of genitalia as it represents $25.6 \%$ in contrast it was $44.4 \%$ in those who made internal washing with fingers.

\section{Discussion}

The aim of this study was to assess the awareness regarding vaginal discharge among women. It was achieved through answering the research questions. More than half of the women had bad knowledge about vaginal discharge. About two thirds of women went for medical examination when they complained of abnormal vaginal discharge and more than one third of them did not seek medical examination due to various causes such as shyness from reveal the genitalia and abnormal vaginal discharge was simple problem from their point of view. There was a highly statistical significant relation between women level of knowledge and using reusable sanitary pad and presence of abnormal vaginal discharge.

Concerning to the knowledge about vaginal discharge, more than half of the women had bad knowledge score, more than one third had fair knowledge score and only two percent of them had good knowledge score level, this result was in the agreement of $\boldsymbol{L i}$ et al., (2010) who conducted a descriptive study among rural women in China aimed to assess knowledge, practice, and prevalence of reproductive tract infection, they assured that the level of knowledge regarding reproductive tract infection was very low among the studied group. 
In the same line, Dube\& Sharma (2012) conducted a comparative study to evaluate the knowledge, attitude and practice regarding reproductive health among urban and rural girls in India, the study was carried out with the aim to assess the level of awareness towards reproductive health. The results revealed that there was decrease of basic awareness regarding reproductive health and the majority of the respondents had a lot of ignorance.

Also, the study findings was in agreement with Suja\& Aruna (2014) who assured in their descriptive study about the knowledge on reproductive tract infection among married women at India that $64 \%$ of the studied group had inadequate knowledge on reproductive tract infection. Also the study findings was in agreement with Mohamed et al (2013) who conducted a descriptive study to evaluate the health practices of respondents regarding to the prevention of the genital tract infection in Benha University, Egypt, they assured in their study that the most of the students had unsatisfactory knowledge score level about genital tract infection.

Moreover, the study findings was in agreement with Hegde et al., (2013) who assured that knowledge regarding reproductive tract infection was poor while the prevalence of reproductive tract infection was high $(26.8 \%)$ and the treatment-seeking behavior was inadequate. On the other hand the current study was in contrast with Şatıroğlu et al., (2012) who conducted a qualitative study; to determine, the knowledge, attitudes and practices of the studied group regarding vaginal discharge and vaginal douche. Their results showed that majority of the studied group had stated that they enabled to differentiate between the normal and abnormal vaginal discharge.

Concerning to seeking medical examination, two thirds of the women sought medical examination when complained of abnormal vaginal discharge. The most prominent causes for seeking medical examination were fear from serious diseases among one third of them and inability to tolerate the abnormal symptoms among more than quarter of them. On the other hand, one third of the studied group did not seek medical advice when they had complained of abnormal vaginal discharge, more than one third of them didn't seek examination because they considered that the abnormal vaginal discharge as simple problem and there was no need for examination, others; more than one third of them were not examined because they feel shyness from reveal the genitalia.

This finding in agreement with $\mathbf{L i}$ et al., (2010) study results among rural women in China to evaluate knowledge, practice and prevalence of genital tract infection, results showed that women who complained of abnormal vaginal discharge did not seek medical treatment unless it interfered with daily routine work, the reason was being shame and very embarrassed to reveal the genital area. Also the present study is agreement with Prusty \& Unisa (2013), who assured in his paper that the awareness and seeking medical treatment was bad among the studied women.

Concerning the practice regarding to menstrual hygiene in the current study the majority of the studied group were used disposable sanitary pad, and approximately one fifth of group were used reusable sanitary pad during menses this was in agreement with El-Gilany et al., (2005)who conducted a descriptive study among urban and rural girls in Mansoura, Egypt, to evaluate menstrual hygienic practices among school of adolescent girls at Mansoura city, results showed that two-thirds of the studied group (66.8\%) used disposable pads, while $28 \%$ of them used re-usable pads as ( cloths or old pieces of cloth ) which discarded after use.

The present study result was in contrast with Abd Elrahim et al., (2012) results as it showed that (29\%) of the women were used (washed reusable clothes) which dried inside home. The present study was in line with El-Gilany et al., (2005) this may be due to the two studies were done in the same geographical place (Mansoura) in contrast the study of Abd Elrahim et al., (2012) was in the east of Egypt which far from Mansoura this lead to changes in the level of knowledge and customs.

There was significant difference in those women regarding the type of underwear; women who used cotton underwear were less in complaining of abnormal vaginal discharge than those who didn't wear cotton underwear, This may be due to wearing cotton under wear is comfortable and the cotton material of the under wear absorb the sweating and provide ventilation to the genital area on the other hand the under wear which made of synthetic material as silk or nylon not absorbent and prevent air flow which increase the sweating and irritation of the genital area. In the present study more than two thirds of the women were used cotton under wear this finding was not accordance with study done by Abd Elrahim et al., (2012) who identified that about half (54\%) of the studied used cotton under wear and $27 \%$ of them used both cotton and nylon ones.

Concerning the presence of abnormal vaginal discharge, the current study findings revealed that about the quarter of the studied group complained of abnormal vaginal discharge, these findings were in agreement with Chaudhary et al., (2012), who reported in their study about prevalence and determinants of vaginal secretions among women who is sexually active in the tertiary care hospital of northern India that the prevalence of vaginal discharge was $24.6 \%$.

Also Singh et al., 2007 reported in their study (vaginal discharge; its causes and associated symptoms which perceived by rural north Indian women), that the prevalence of vaginal discharge was $28.7 \%$. Also, Komal et al., (2014) reported that the prevalence of abnormal vaginal discharge was $26.3 \%$ in their study about infertility, depression, anxiety of married woman and its relations with genital tract infections in rural place of India. The 
finding also is in agreement with Mohammed et al., (2015) who reported that $28.2 \%$ of the studied group complained of abnormal vaginal discharge and the more commonly color of discharge was whitish (16.9\%) but in the present study about more than half of the women complained of white vaginal discharge as they reported.

The present study results were in contrast to Mahmood et el., (2011) who conducted a study about the causes and management of pathological vaginal discharge their results showed that $6.4 \%$ of the studied group complained of abnormal vaginal discharge, this variation in the rates between both studies could be due to the small studied sample of their study because their study sample was 30 female patient in contrast to 500 in the present study.

Also the present study contradicts the study of Abbas et al., (2016) who reported that only (8.2\%) of studied group were suffering from abnormal vaginal discharge. The difference of both study results may be due to the less usage of contraceptive method in their study sample $63.8 \%$ were non-contraceptive users on the other side about two thirds of the women were used contraceptive methods.

Regarding to the characteristics and associated symptoms of vaginal discharge, more than two thirds of the women had complained from itching, about half of the women complained of white vaginal discharge, and about two thirds of the women complained of lower abdominal pain. These findings were in agreement with Chaudhary et al., (2012) who reported in their study about the prevalence and determinants of vaginal secretion among sexually active women in India that gynecological symptoms like itching, lower abdomen pain were found to be strongly correlated with abnormal vaginal discharge in the study.

Although these studies regarding vaginal discharge and reproductive tract infection from different countries in the world, the results showed that the complaint of vaginal discharge is very common. This may be due to poor access to health care, poor knowledge and some of reproductive tract infection are asymptomatic are responsible for increased prevalence of genital tract infection. These indicate that there is strong need for increase awareness of the communities all over the world about the reproductive health.

In the current study there was statistical significant difference between the total knowledge score level and complaining of abnormal vaginal discharge among women, findings showed that there was decreased in abnormal vaginal discharge with increased level of knowledge score, Thus when knowledge level improves, the discharge will decreased. This result is in agreement with Mohamed et al., (2013) \& Bobhate\& Shrivastava (2011) who mentioned that there was significant association between having good knowledge and good practice regarding reproductive tract infection.

In the present study there was significantly statistically difference in women who used disposable sanitary pad and those who used reusable sanitary pad. There was increase in the abnormal vaginal discharge in those women who used reusable sanitary pad than those who used disposable sanitary pads. This may be due to the repeated use of unclean cloth and in adequate drying of re-usable cloth before using it again, which results in harboring of bacteria which result in increasing the vaginal infections.

This finding was in agreement with Ananda et al., (2015) who conducted their study to evaluate the practices regarding menstrual hygiene and its relationship with genital tract infections and abnormal vaginal secretions among women in India, the results showed that $15 \%$ of women used sanitary pad during menstruation in India. Both reproductive tract infection and abnormal vaginal discharge were positively related with non-use of hygienic practices. The women who used unhygienic method during menstruation were more likely to have reproductive tract infection.

\section{Conclusion}

Based on the present study results, more than half of the employees had poor awareness about vaginal discharge. In addition, about quarter of the studied women complained of abnormal vaginal discharge. Abnormal vaginal discharge was decreased in the women who had good knowledge score, and who used good hygienic practices, in contrast, there was increase in the abnormal vaginal discharge in those women who had poor knowledge score, who didn't seek examination till they cannot tolerate the symptoms, who didn't examine except the husband complain and also who used reusable sanitary pads.

\section{Recommendation}

Based on the results of the current study, the following suggestions are recommended:

Developing a health education program for raising awareness about the vaginal discharge through maternal and child health centers, mass media, schools, universities and social clubs.

\section{For further researches}

Further researches needed to investigate the women who complain of abnormal vaginal discharge to determine the type and causes of abnormal vaginal discharge.

Limitation of the study

There were some problems faced the researcher when she was collected the data as the following: 
- Some women felt embarrassed to discuss the research topic especially who were virgin.

- Some women were busy and had no time to fill in the sheet.

- There was not a suitable place to speak to the women and to collect the data.

- Some old women were not cooperative with the researcher

\section{Acknowledgement}

The author is gratified to all women who participated in the study. Finally gratifying merci for all persons who help in publishing this article.

\section{References}

[1]. Abbas, A.H., Shaaban, O.M., Badran, S.M., Shaltout, A.S., Nasr, A., and Abdullah, S.A. (2016): Risk factors and health hazards about vaginal infections in Upper Egypt: Across Sectional Study, women's health center, Assiut University, Assiut, Egypt, Thai journal of Obstetrics and Gynaecology, 24:(1), pp: 50-56 .

[2]. Abd Elrahim, H.A., Nagieb, S., Mohamed, S.N., Hafez, A., and Kamel, H. (2012): Role of Unhealthy Practices during the Menstrual, Partum and Postpartum Periods as Risk Factors for Secondary Infertility. Egyptian Journal of Nursing (EJN), 1(4), p: 92.

[3]. Ananda, E., Singhb, J., and Unisaa, S. (2015): Menstrual hygiene practices and its association with reproductive tract infections and abnormal vaginal discharge among women in India, Sexual \& Reproductive Healthcare, 6(4), pp: $249-254$.

[4]. Bobhate, P \& Shrivastava, S. (2011): Cross Sectional Study of Knowledge and Practices about Reproductive Health among Female Adolescents in an Urban Slum of Mumbai, journal of Family and Reproductive Health. 5(4): pp: 117-124.

[5]. British Medical Journal (BMJ), (2013): Abnormal vaginal discharge, BMJ 2013; 347:f4975 doi: 10.1136/bmj. f4975 (published 13 August 2013) available at http://www.epocrates.com/dacc/1308/AbnormalVaginalDischargeBMJ1308.pdf last accessed on $31 / 10 / 2016$.

[6]. Chaudhary, V., et al, (2012): Prevalence and Determinants of Vaginal Discharge among Women of Reproductive Age Group in Tertiary Care Hospital of Northern India. Natl J Community Med. 3(4), pp: 661-5.

[7]. Dube, S., \& Sharma, K. (2012): Knowledge, Attitude and Practice Regarding Reproductive Health among Urban and Rural Girls: A Comparative Study, Ethno Med, 6(2), pp: 85-94 .

[8]. El-Gilany, A., Badawi, K., and El-Fedawy, S. (2005): Menstrual Hygiene among Adolescent School girls in Mansoura, Egypt, Reproductive Health Matters 2005; 13(26):147-152. Available at http://www.rhm-elsevier.com/article/S0968-8080 (05)26191-8/pdf last accessed on 16/5/2016. Elsevier, Philadelphia, pp 480,481.

[9]. Hegde, S.K., et al, (2013): Reproductive tract infection s among women in a peri-urban under privileged area in Bangalore. India, Annals of Tropical medicine and Public Health. 6 (2), pp: 215-220.

[10]. Hirsch, L. (2013): Vaginal Discharge: What's Normal, What's not, available at http://kidshealth.org/PageManager.jsp?dn=KidsHealth\&lic=1\&ps=207\&cat_id=20015\&article_set=20385 last accessed on $2 / 11 / 2015$

[11]. Komal, T, P., et al, (2014): Fertility Profile, Anxiety, Depression of Married Women and Its Association with Reproductive Tract Infections in the Rural Area of Surendranagar District, Scholars Journal of Applied Medical Sciences, 2(1A), pp:104-108.

[12]. Kumar S \& Padmaja (2016): Reproductive Tract Infections - Clinic epidemiological Study Among Women Attending Tertiary Health Care Center, Ananthapuramu District, Andhra Pradesh. IOSR Journal of Dental and Medical Sciences (IOSR-JDMS). 15(4).

[13]. Li, C., et al, (2010): knowledge, behavior and prevalence of reproductive tract infection: A descriptive study on rural women in Hunchun, China. Asian Nursing Research, 4: (3), pp: 122-129.

[14]. Mahmood, K.T., \& Farheen, \& Z. Farah, S. \& Marium, Z. and Fatma, A. (20 11): causes and management of pathological vaginal discharge, journal of pharmaceutical science and technology, 3(1), pp: 448-455.

[15]. Maria, M.V., Juraci, A., Cesar, J.A., Raúl, A., Mendoza-Sassi, R. A., and Schmidt, E.B. (2013): Pathological Vagina Discharge among Pregnant Women: Pattern of Occurrence and Association in a Population-Based Survey. Obstetrics and Gynecology International, Volume 2013 (2013), Article ID 590416, 7 pages available at http://dx.doi.org/10.1155/2013/590416 last accessed on 23/6/2016.

[16]. Mohamed, H.A., El-Beih, A., Dawah, A., and Abd- El Aal, E. (2013): Health Practices among Female University Students Regarding Prevention of Reproductive Tract Infections, Master Thesis, Faculty of Nursing, Benha University.

[17]. Mohammed, A., et al., (2015): Pattern of Vaginal Discharge and Associated Demographic Characteristics among Female Patients Seen at a Gynaecology Clinic in Northern Nigeria. Open Access Library Journal, 2, e2231 PP. 1-8 available at http://www.oalib.com/articles/3154074\#.V0BXjPITLIV last accessed on 1/1/2016.

[18]. Prusty, R.K., \&Unisa, S. (2013): Reproductive Tract Infections and Treatment Seeking Behavior among Married Adolescent Women in India, Conference 2013, Busan, South Korea.

[19]. Şatıroğlu, N., Hıdıroğlu, S., and Karavuș, M. (2012): Vajinal Akıntı Hakkındaki Bilgi, Tutum ve Davranışlar Saptamaya Yönelik Niteliksel Bir Çalışma) A Qualitative Study to Defıne, Knowledge, Attitudes and Practices of about Vaginal Discharge in Istanbul), TAF Preventive Medicine Bulletin, 11(5): pp: 545 - 558.

[20]. Shaaban, O. M., et al, (2013): vaginal douching by women with vulvo vaginitis and its relation to reproductive health hazards, department of obstetrics and gynecology, faculty of medicine, Assiut university, Assiut, Egypt, Bio Med Central Women's health, last accessed on 23/8/2016.

[21]. Singh, A. J., (2007): Vaginal discharge: Its causes and associated symptoms as perceived by rural north Indian women Indian Journal of Community Medicine; 32(1) PP: 22-26.

[22]. Sobel, J., (2015): Patient information: Vaginal discharge in adult women (Beyond the Basics) Up To Date journal. Available at http://www.uptodate.com/contents/vaginal-yeast-infection-beyond- 
thebasics?source=search_result\&search=patient+information+vaginal+discharge+in+adult+woman+sobel\&selectedTitle=4\%7E150 last accessed on 8/11/2015.

[23]. Sobel, D.J., (2011): Diagnostic approach to women with vaginal discharge or vulvovaginal symptoms. Available at: www.uptodate.com (Accessed Oct, 2011).

[24]. Suja, B., \& Aruna, S. (2014): Knowledge on Reproductive tract infection among married women at selected rural area-a descriptive study, Internal Journal of Comprehensive Nursing.1; (1).

[25]. WebMD, (2015): You're Guide to the Female Reproductive System, Available at http://www.webmd.com/sexrelationships/guide/your-guide-female-reproductive-system last accessed on 6/11/2015 